\title{
Projeto Kaya: Design Centrado no Jogador para uma Plataforma Gamificada de Apoio à Colaboração no Ensino
}

\author{
Vinicius Santos \\ Instituto Federal de São Paulo \\ Guarulhos, São Paulo, Brasil \\ v.costa@aluno.ifsp.edu.br
}

\author{
Leticia Souza \\ Instituto Federal de São Paulo \\ Guarulhos, São Paulo, Brasil \\ leticia.rejane@aluno.ifsp.edu.br
}

\author{
Yves Maia \\ Instituto Federal de São Paulo \\ Guarulhos, São Paulo, Brasil \\ yves.g@aluno.ifsp.edu.br
}

\author{
Ticianne Darin \\ Instituto UFC Virtual \\ Universidade Federal do Ceará \\ Fortaleza, Ceará, Brasil \\ ticianne@virtual.ufc.br
}

\author{
Thiago Barcelos \\ Laboratório de Computação Aplicada - LABCOM ${ }^{3}$ \\ Instituto Federal de São Paulo \\ Guarulhos, São Paulo, Brasil \\ tsbarcelos@ifsp.edu.br
}

\begin{abstract}
RESUMO
A colaboração é tida como um aspecto facilitador da aprendizagem em várias teorias pedagógicas. Por outro lado, estratégias baseadas em Aprendizagem Baseada em Jogos (ABJ) e na gamificação de ambientes de aprendizagem têm sido propostas. No entanto, poucas soluções têm sido propostas na comunidade brasileira que incorporem recursos tecnológicos dos dispositivos móveis, tais como a geolocalização, em ambientes gamificados de suporte ao ensino. Os múltiplos desafios vinculados à compreensão das necessidades do público-alvo de sistemas interativos voltados à educação motivaram o desenvolvimento desta pesquisa. $\mathrm{O}$ artigo apresenta o estudo de caso de um processo de Design Centrado no Jogador para a Kaya, uma plataforma gamificada que visa suportar explicitamente a colaboração entre participantes. Pesquisas com alunos e professores indicam, por um lado, a predisposição de alunos em colaborarem entre si, e a dissociação, na concepção dos professores, entre um jogo e uma atividade colaborativa, bem como a dificuldade de avaliar individualmente os participantes de uma atividade colaborativa. O design da plataforma Kaya, que levou esses fatores em consideração, é detalhado, e as considerações e lições aprendidas sobre o processo são apresentadas.
\end{abstract}

\section{PALAVRAS-CHAVE}

Gamificação, Ensino, Design Centrado no Jogador

Permission to reproduce or distribute, in whole or in part, material extracted from this work, verbatim, adapted or remixed, as well as the creation or production from the content of such work, is granted without fee for non-commercial use, provided that the original work is properly credited.

IHC 2019 - Workshop sobre Interação e Pesquisa de Usuários no Desenvolvimento de Jogos (WIPlay), Outubro 21-25, 2019, Vitória, Brasil. In Anais Estendidos do XVIII Simpósio Brasileiro sobre Fatores Humanos em Sistemas Computacionais. Porto Alegre: SBC.

(C) 2019 by the author(s), in accordance with the terms of the Creative Commons Attribution-NonCommercial 4.0 International Public License (CC BY-NC 4.0).

\section{Introdução}

A colaboração é um dos aspectos comportamentais vinculados ao estudante que é considerado como um facilitador da aprendizagem em várias teorias pedagógicas. Provavelmente a mais famosa é a Teoria Sócio-Cultural de Vygotsky [20], que postula que o desenvolvimento da criança e do adolescente é moldado pelo ambiente social e cultural. O construcionismo, proposto por Papert [14], também parte da ideia que o conhecimento pode ser produzido por meio da construção de artefatos construídos de forma colaborativa entre estudantes.

Por outro lado, os jogos fazem parte do desenvolvimento intelectual e social das crianças desde a primeira infância. Piaget observa que as brincadeiras infantis assumem ao longo do tempo formatos mais estruturados em termos das regras utilizadas, se aproximando cada vez mais dos jogos, à medida que o pensamento abstrato se desenvolve [2]. De forma complementar, Vygotsky [21] afirma que as regras dos jogos, exercitadas de forma social, permitem o desenvolvimento de funções cognitivas superiores.

Mais recentemente, houve o advento e popularização dos jogos digitais disponíveis em diferentes plataformas computacionais (computadores, celulares, tablets, consoles de videogame, entre outras). Nesse contexto, ganha força o argumento que o aspecto lúdico por um lado é incentivado nos primeiros estágios da educação escolar mas, por outro, é progressivamente abandonado como estratégia à medida que $\mathrm{o}$ aluno avança para o ensino médio e superior. Paralelamente, os jogos digitais se constituem como uma mídia com a qual os alunos continuam interagindo fora da escola. Prensky [16] propôs o conceito de Aprendizagem Baseada em fogos (ABJ), segundo o qual jogos digitais podem ser construídos para ensinar conteúdos nas escolas e empresas, engajando os participantes.

Apesar de estudos recentes confirmarem a efetividade da ABJ [5] algumas críticas a esse conceito também foram feitas. Uma delas é que, como a atividade de jogar é voluntária, "impor" 
um jogo como ferramenta pedagógica pode violar um princípio básico do engajamento à atividade. No contexto brasileiro, uma limitação é a pouca disponibilidade de jogos com nível de qualidade adequado [9], além da ênfase excessiva em um aspecto conteudista no processo de design, sem considerar o aspecto lúdico inerente aos jogos $[1,7,6]$.

Uma estratégia alternativa para engajamento é a gamificação [8], entendida como a utilização de aspectos dos jogos, tais como pontuação, objetivos e enredo, em contextos alheios aos próprios jogos. No contexto educacional, Ogawa, Klock e Gasparini [12] demonstraram por meio de um mapeamento sistemático da literatura que a utilização de aplicações com aspectos de gamificação contribuiu na motivação, no acerto dos exercícios ou tarefas, na assiduidade, na satisfação e no engajamento de estudantes.

Vale observar que um diferencial de aplicações comerciais gamificadas bem sucedidas é o uso de informações de geolocalização, em alguns casos em tempo real, de modo a compartilhar a localização física dos usuários e criar novas formas de engajamento [3] - e, mesmo, novas mecânicas de interação no caso de jogos. Lemos [10] definiu o termo jogos móveis locativos para descrever a categoria de jogos digitais que utilizam dispositivos móveis e seus sensores, em especial a geolocalização, para fazer do espaço público o espaço do jogo. Exemplos recentes de jogos móveis locativos incluem o Pokemon Go e o Zombie Run [3].

A partir do contexto apresentado, verificou-se o desafio de propor um sistema interativo de forma a preencher as lacunas encontradas na literatura que, ao mesmo tempo, trouxesse as características de engajamento tipicamente encontradas em jogos e aplicações gamificadas e não tivesse uma apresentação excessivamente "travada" ou conteudista, propondo atividades que fomentassem a colaboração entre diferentes participantes. A complexidade do desafio, bem como a necessidade de aproximar o sistema interativo de um contexto de utilização real, levando em consideração os princípios de design para gamificação de atividades levou os autores a optar por técnicas do Design Centrado no Jogador $[19,18]$ para a definição do seu conceito e funcionalidades.

Dessa forma, este artigo apresenta o design de interação da Kaya, uma plataforma personalizável que visa apoiar professores na proposição de desafios a seus alunos, fomentando ao mesmo tempo a colaboração entre eles. Serão descritos o processo de levantamento de necessidades e perfis de usuário dos dois públicos-alvo do sistema, professores e alunos do ensino técnico integrado ao ensino médio, no Instituto Federal de São Paulo, bem como o processo de design conceitual e prototipação da plataforma.

\section{Revisão da literatura}

\subsection{Trabalhos anteriores}

Como identificação preliminar do potencial inovador da aplicação, foi realizado um mapeamento da literatura nas bases de dados de duas conferências brasileiras que reúnem a pesquisa em jogos digitais (Simpósio Brasileiro de Jogos e Entretenimento Digital - SBGAMES) e a pesquisa em Informática na Educação
(Congresso Brasileiro de Informática na Educação - CBIE). Foram buscados artigos publicados nas conferências entre os anos de 2015 e 2018 cujo texto completo atendesse à seguinte string de busca: ("jogos móveis locativos" OU "geolocalização" OU "gamificação") E "educação". A partir da definição do intervalo temporal, a busca foi feita de forma semi-automatizada no Portal de Publicações da Comissão Especial de Informática em Educação da $\mathrm{SBC}^{1}$, que hospeda os anais do CBIE e de forma manual no portal da Comissão Especial de Jogos e Entretenimento Digital ${ }^{2}$, que possui apontadores para os anais de cada edição do SBGAMES. Os resultados, segmentados por ano e presença de cada uma das palavras-chave buscadas, são apresentados na Tabela 1.

\section{Tabela 1: Resultados do levantamento preliminar da} literatura

\begin{tabular}{|l|c|c|c|c|c|}
\hline Tema (presença da palavra- & \multicolumn{5}{|c|}{ Ano de publicação } \\
\cline { 2 - 6 } chave de busca) & 2015 & 2016 & 2017 & 2018 & Total \\
\hline Jogos Móveis Locativos & 0 & 0 & 1 & 0 & 1 \\
\hline Geolocalização & 0 & 0 & 0 & 0 & 0 \\
\hline Gamificação & 8 & 14 & 10 & 12 & 44 \\
\hline Gamificação + Geolocalização & 0 & 2 & 0 & 0 & 2 \\
\hline Total & 8 & 16 & 11 & 12 & 47 \\
\hline
\end{tabular}

Os resultados indicam uma maior quantidade de trabalhos que referenciam de alguma forma o conceito de gamificação nos últimos anos, com um total de 44 artigos. Por outro lado, o termo geolocalização não aparece de forma isolada em nenhum trabalho dentro do período analisado, mas sim conjuntamente com o conceito de gamificação.

Pinto e Malfatti [15] apresentam o desenvolvimento de um jogo onde desafios propostos por um professor exigem que os estudantes tirem fotos e identifiquem sua localização com o apoio do sensor de GPS de um celular. Apesar da proposta se aproximar do objetivo deste trabalho, considera-se uma limitação o fato do jogo não envolver a colaboração entre os estudantes e ter a sua mecânica de pontuação baseada unicamente na quantidade de tarefas cumpridas com sucesso dentro de um tempo estipulado.

No outro trabalho que envolve os dois conceitos, Oliveira et al. [13] apresentam uma plataforma que utiliza a geolocalização em dispositivos móveis para permitir a notificação e identificação de focos do mosquito Aedes aegypti. Os usuários são estimulados a manter o uso por meio de recompensas como a disponibilização de rankings e reconhecimento público do desempenho dos participantes. Uma validação preliminar da plataforma indica um potencial benefício da mesma no combate ao mosquito e como recurso didático. No entanto, as mecânicas de jogo incorporadas não estimulam a colaboração entre usuários (e, sim, a colaboração do usuário com o bem comum) e

\footnotetext{
${ }^{1}$ http://www.br-ie.org/pub/index.php/sbie

http://www.sbgames.org
} 
a plataforma tem finalidade bem específica, tendo apenas como possível derivação o uso com finalidade educacional.

A única referência identificada com relação a jogos móveis locativos é o trabalho de Moura et al. [11], que descrevem uma ferramenta de autoria para que professores sem conhecimentos técnicos possam produzir um jogo locativo. Há dois tipos de atividades possíveis dentro do jogo criado: responder a um quiz e capturar um objeto de realidade aumentada, ambos vinculados a localização do usuário em um ponto específico do espaço urbano.

Embora o mapeamento realizado tenha caráter preliminar e não exaustivo, seus resultados permitem a identificação de algumas tendências de pesquisa, ao menos nas principais comunidades de pesquisa no Brasil. É possível observar alguns avanços na incorporação de aspectos lúdicos juntamente com tecnologias de geolocalização em sistemas móveis para apoio à educação, inclusive possibilitando ao próprio professor criar desafios. No entanto, as mecânicas de jogo incorporadas às soluções existentes não permitem muitas variações e não apoiam de forma explícita a colaboração. Nesse sentido, os resultados identificados motivaram o uso de técnicas de Design Centrado no Jogador para melhor compreender as motivações de professores e alunos relacionadas ao uso de jogos e tecnologias na educação e dos padrões de comportamento relacionados à colaboração.

\subsection{Processo de game design}

Considerando o processo de game design como uma atividade interdisciplinar, e ainda considerando as características de motivação que devem estar presentes na plataforma a ser desenvolvida neste projeto - em especial, a motivação para a colaboração entre os pares - optou-se por utilizar o processo de desenvolvimento P-III preconizado por Abeele et al. [19] para o projeto e desenvolvimento de jogos sérios. O processo prevê o desenvolvimento iterativo e incremental, com três fases que definem pontos de verificação para a continuidade do projeto:

(i) Design do Conceito: tem por objetivo usar o conhecimento adquirido sobre o grupo de jogadores e o domínio do problema para obter um primeiro conceito sobre o jogo

(ii) Design do Jogo: visa definir e detalhar o projeto do jogo de forma a gerar insumos para o trabalho de desenvolvedores e artistas digitais

(iii) Desenvolvimento do Jogo: etapa final, que envolve a programação e projeto de arte em si, bem como testes de baixa e alta fidelidade e playtests.

O estágio atual do projeto, que será descrito na sequência do artigo, envolve a fase (i) do processo, bem como o início da fase (ii), com o desenvolvimento de um storyboard que detalhe o conceito inicial produzido. O modelo foi escolhido por sua compatibilidade com o conceito de um processo mais amplo de Design de Interação e pela importância dos aspectos motivacionais que se pretende incorporar à plataforma. Ainda, o aspecto de design participativo preconizado no processo é incorporado pelo fato de parte dos autores serem também alunos e potenciais usuários da plataforma.

\section{Design do Conceito: Levantamento de perfil e necessidades dos usuários}

A partir da identificação de uma lacuna nos trabalhos descritos na literatura - a ausência do estímulo à colaboração entre participantes de um jogo ou atividade gamificada de apoio ao ensino - a pesquisa de campo deste trabalho teve como principal objetivo compreender como a colaboração está presente no processo de ensino-aprendizagem, do ponto de vista dos seus principais atores: professores e alunos. Segundo Skyes e Federoff [18], uma identificação adequada do perfil do futuro jogador pode trazer informações relevantes sobre a experiência de jogo que será apreciada por ele. Sweetser e Johnson [17] discutiram o uso de técnicas bem estabelecidas em IHC, como o grupo de foco e questionário, para a identificação de hábitos, preferências e experiências de jogadores.

A princípio, o principal público esperado para a plataforma são alunos e professores do ensino médio. Isso se deve ao acesso facilitado ao campo, já que como mencionado anteriormente, parte dos pesquisadores são também alunos do Instituto Federal de São Paulo. Dessa forma, foram definidos dois instrumentos de coleta de dados, que serão descritos a seguir.

\subsection{Questionário com alunos}

A utilização do questionário surgiu em um momento inicial da pesquisa quando, por meio do contato com professores e alunos, identificou-se uma turma do segundo ano do Curso Técnico em Informática para Internet integrado ao Ensino Médio cujos alunos seriam muito colaborativos entre si, em especial em situações que exigem um maior empenho como, por exemplo, às vésperas de uma avaliação em uma disciplina em que muitos estão com notas baixas. De forma a validar essa hipótese, o questionário foi então preparado utilizando a plataforma Google Forms, com três questões:

(1) Em que disciplinas você teve notas "vermelhas" (abaixo de 6,0) nas provas?

(2) Em que disciplinas você tem mais dificuldades?

(3) Você está disposto a ajudar um(a) colega em dificuldade se tiver mais segurança que ele(a) em uma disciplina?

O questionário foi divulgado junto aos alunos do Ensino Médio, tendo recebido 40 respostas no período de 25/04/2019 a $10 / 05 / 2019$.

\subsection{Entrevista com professores}

A coleta de dados com professores partiu de uma hipótese prévia indicando que fomentar e, principalmente, avaliar os resultados da colaboração seriam desafios para esse público. Dessa forma, a entrevista semi-estruturada foi definida com as seguintes perguntas:

1) Que ações você toma para estimular a colaboração entre os alunos?

2) Você considera que essas ações estão sendo bem sucedidas?

3) Porque você escolheu essa estratégia para incentivar a colaboração?

4) Você buscou ideias com outras pessoas? Quais?

5) Enfrentou problemas? Quais? 
6) Como você acha que os alunos se sentiram? E você sentiu diferença?

7) Os objetivos relacionados aos conteúdos propostos foram alcançados?

8) Todos os alunos participaram? Se não, como considera que seria possível melhorar ou incluir todos?

9) Que tipo de tecnologia você já usou em suas aulas?

10) Você já usou jogos digitais em suas aulas?

11) Você já usou algum tipo de recurso baseado em celulares em suas aulas?

As perguntas de 1 a 5 tiveram como objetivo identificar possíveis estratégias utilizadas pelos entrevistados para fomentar a colaboração e fontes de inspiração para definir tais estratégias. As perguntas 6 a 8 buscaram identificar a avaliação do entrevistado quanto às estratégias empregadas e sua percepção quanto ao engajamento dos alunos, enquanto que as perguntas 10 a 12 visaram identificar a experiência dos entrevistados com recursos digitais em suas aulas, como foco nos jogos digitais e dispositivos móveis.

As entrevistas foram realizadas entre os dias 21/05/2019 e $13 / 06 / 2019$ e envolveram quatro professores que atuam no ensino médio do Instituto Federal de São Paulo, nas disciplinas de Língua Portuguesa, Matemática, Biologia e Geografia. As entrevistas foram gravadas e transcritas posteriormente para seleção e agrupamento dos temas mencionados com base na sua frequência na fala dos participantes. $O$ processo de análise foi iterativo, seguindo os princípios da Teoria Fundamentada em Dados [4], onde a cada nova entrevista foi feito um refinamento do agrupamento de temas, sendo que a análise final foi realizada por meio da codificação axial.

\subsection{Resultados}

Na Figura 1 são apresentados os resultados da primeira pergunta do questionário, onde é possível verificar que os respondentes indicaram que, naquele momento, a maior quantidade de notas baixas se encontrava nas disciplinas de Matemática, História, Química e Física.

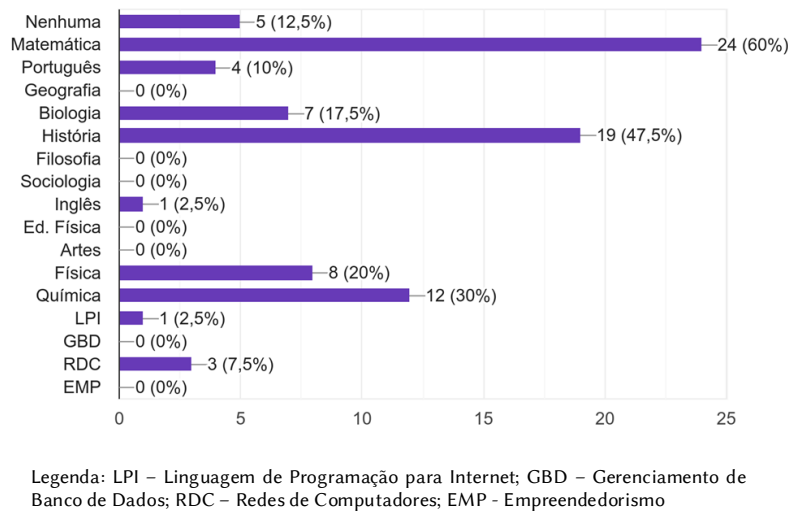

Figura 1: Percentual de notas baixas em disciplinas dentre os respondentes do questionário
Quanto às disciplinas nas quais os alunos apresentam maiores dificuldades, destacam-se Matemática, Química, Física e Biologia, nesta ordem, como pode-se observar na Figura 2.

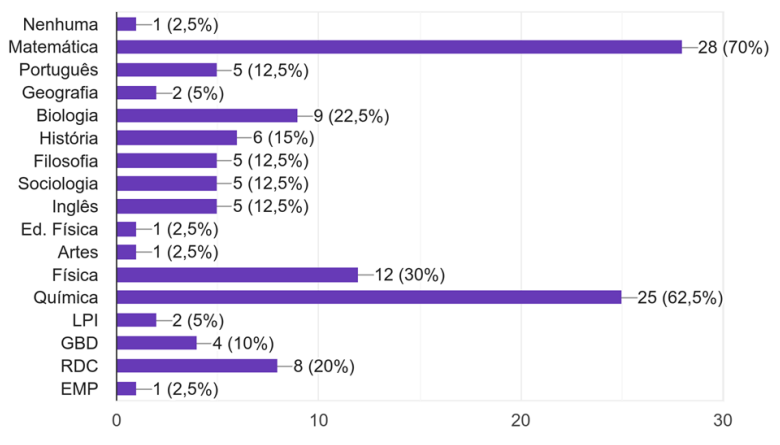

Legenda: LPI - Linguagem de Programação para Internet; GBD - Gerenciamento de Banco de Dados; RDC - Redes de Computadores; EMP - Empreendedorismo

Figura 2: Percentual de disciplinas em que os respondentes do questionário encontram dificuldades

Por fim, dos 40 respondentes, 27 indicaram que ajudariam um colega em dificuldades com uma disciplina, confirmando a hipótese de uma maior predisposição à colaboração nesse público.

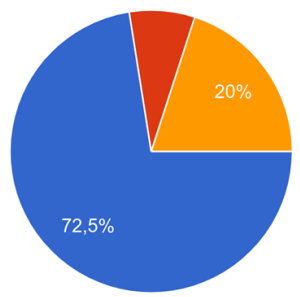

$$
\text { Sim }
$$$$
\text { Talvez }
$$

Figura 3: Predisposição dos alunos para auxiliar colegas em disciplinas com dificuldades

A análise temática das entrevistas permitiu a identificação de cinco categorias temáticas nas falas dos professores: vantagens da abordagem colaborativa, dificuldades para obter colaboração entre alunos, práticas adotadas para fomentar a colaboração, vantagens da abordagem por jogos e dificuldades para incorporar jogos e tecnologias. As unidades de análise dentro de cada categoria são apresentadas a seguir na Tabela 2.

Como uma análise completa das unidades de análise envolve necessariamente uma discussão de aspectos educacionais, que fogem ao escopo deste artigo, serão destacadas neste momento as unidades de análise que geraram maiores subsídios para o processo de game design. Deve-se destacar, na categoria (C5), a unidade "fomento à competição". Os entrevistados foram quase unânimes em afirmar que, em sua concepção, os jogos podem provocar um aumento indesejado da competição entre alunos. Ainda, na categoria (C3), destacam-se as menções ao uso de recursos tecnológicos tais como o uso de vídeo-aulas, questionários online e jogos. Verifica-se que a maioria desses recursos apresentam conteúdo e apresentação previamente definidos, limitando ou impedindo um protagonismo do 
Tabela 2: Categorias e unidades de análise - codificação axial dos dados da entrevista

\begin{tabular}{|c|l|}
\hline Categoria & Unidades de análise \\
\hline $\begin{array}{c}\text { (C1) Vantagens da } \\
\text { abordagem } \\
\text { colaborativa }\end{array}$ & $\begin{array}{l}\text { Autonomia } \\
\text { Melhor relacionamento entre alunos }\end{array}$ \\
\hline $\begin{array}{c}\text { (C2) Dificuldades para } \\
\text { obter colaboração entre } \\
\text { os alunos }\end{array}$ & $\begin{array}{l}\text { Avaliar a colaboração individual é difícil } \\
\text { Auto-estima e timidez limitam a integração } \\
\text { Diferenças entre indivíduos podem gerar } \\
\text { conflitos }\end{array}$ \\
\hline $\begin{array}{c}\text { (C3) Práticas adotadas } \\
\text { para fomentar a } \\
\text { colaboração }\end{array}$ & $\begin{array}{l}\text { Trabalhos em grupo } \\
\text { Auto-avaliação } \\
\text { Uso de recursos tecnológicos “prontos" }\end{array}$ \\
\hline $\begin{array}{c}\text { (C4) Vantagens da } \\
\text { abordagem por jogos }\end{array}$ & $\begin{array}{l}\text { Engajamento dos alunos } \\
\text { Aspecto lúdico dos jogos } \\
\text { Diferenciação das aulas tradicionais }\end{array}$ \\
\hline $\begin{array}{c}\text { (C5) Dificuldades para } \\
\text { incorporar jogos e } \\
\text { tecnologias }\end{array}$ & $\begin{array}{l}\text { Fomento à competição } \\
\text { Limitações na quantidade e qualidade dos } \\
\text { recursos tecnológicos } \\
\text { Limitação de tempo }\end{array}$ \\
\hline
\end{tabular}

professor na criação de atividades. Por outro lado, a questão da dificuldade em avaliar a participação individual dos alunos em atividades coletivas aparece na categoria (C2). No entanto, além de afirmarem que uma abordagem baseada em jogos pode gerar maior engajamento dos alunos (categoria C4) e melhorar seu relacionamento interpessoal (categoria $\mathrm{C} 1$ ), fomentar a avaliação da participação dos alunos por eles mesmos (categoria C3) aparece como uma forma de mitigar a dificuldade em avaliar os resultados individuais da atividade.

Dessa forma, dentro do universo de potenciais usuários pesquisados até o presente momento, foi possível extrair os seguintes insights para o início da etapa de Design do Jogo: está disponível um público de alunos potencialmente disposto a colaborar entre si nos estudos; os professores em geral acreditam no potencial de atividades baseadas em jogos e colaboração, apesar de verem a competição associada aos jogos como um fator prejudicial e de reportarem dificuldades em avaliar como se dá a colaboração entre participantes de uma atividade individual. Esses fatores serão particularmente considerados na produção do conceito e storyboard iniciais da plataforma, que serão apresentados na próxima seção.

\section{Design do Jogo: conceito e storyboard inicial}

A partir dos dados obtidos na primeira fase do processo, foi produzido o conceito inicial da plataforma. Kaya (que significa "cérebro" na língua indígena terena) é proposta como uma plataforma na qual os professores propõem desafios aos alunos. A proposição de desafios visa atender à limitação dos recursos digitais já utilizados, mencionada pelos professores participantes da pesquisa, que não permitem a criação de variações de atividades. Os desafios envolverão, na maior extensão possível, recursos disponíveis no mundo exterior ao jogo. Haverá três tipos de desafio:
- Captura, que envolve a utilização da câmera do celular para a obtenção de uma foto ou vídeo de algum objeto (como um ente ou informação que está sendo estudado, por exemplo), fenômeno, ou evento (como o registro de uma discussão ou debate pelos alunos). Nesse caso, a "captura" deve ser validada pelo professor proponente para que o desafio seja considerado como cumprido.

- Check-in, que envolve que o aluno esteja presente em uma determinada localização geográfica para a sua realização. Nesse caso, a validação será feita automaticamente pela plataforma.

- Questionário, que consiste na resposta a um questionário com questões de múltipla alternativa ou dissertativas.

Os desafios poderão ser compostos por mais de um dos tipos definidos acima. Por exemplo, um desafio de captura pode exigir um check-in em determinada localidade para sua realização, ou um questionário pode exigir um check-in para ser respondido. A utilização do recurso de geolocalização, bem como a captura, visam trazer recursos e atividades do mundo real para a plataforma, com a introdução de aspectos locativos [10]. Cabe ressaltar que o questionário, como modalidade mais "tradicional" de desafio, é incluído com base nas menções dos professores participantes do levantamento, que indicaram familiaridade com esse tipo de atividade online. Espera-se que ela atue como um ponto de partida para a criação de atividades que sejam "aumentadas" com as outras duas modalidades, por meio da composição mencionada anteriormente.

Uma vez que o desafio seja cumprido e validado pelo professor, o aluno fará jus a uma recompensa em uma quantidade de $X P$ (experiência, usando a terminologia corrente nos jogos). Trata-se do mecanismo de bonificação mais comumente utilizado em estratégias de gamificação [8]; no entanto, aqui a bonificação não é aplicada somente ao cumprimento de tarefas, mas também à colaboração entre os participantes de um desafio o que, com base na análise dos trabalhos anteriores, se constitui como o maior diferencial do projeto.

Durante a execução de um desafio, o aluno poderá fazer uma solicitação de ajuda para um contato à sua escolha, havendo também a possibilidade de enviar a solicitação para um contato que esteja fisicamente próximo do local onde se encontra. Os contatos disponíveis são participantes do mesmo desafio do qual o aluno está participando. Se a solicitação de ajuda for aceita, ambos os participantes poderão se comunicar por mensagens para combinar o momento e local do encontro. A mecânica da ajuda exigirá que a colaboração aconteça em um encontro presencial entre os participantes, validado por meio do recurso de geolocalização. Dessa forma, pretende-se novamente estimular o relacionamento interpessoal entre os participantes, conforme indicado no levantamento descrito na seção 3. Ao término da ajuda, a contribuição do participante que ajudou será classificada pelo solicitante, e o participante que prestou a ajuda receberá uma quantidade de $X P$, mas essa vinculada diretamente 
à colaboração prestada. A bonificação diretamente vinculada à colaboração tem como objetivo estimular e premiar esse comportamento - de certa forma, até induzi-lo - bem como introduzir um mecanismo de auto-avaliação dos participantes, já que uma colaboração só será premiada se considerada como satisfatória pelo solicitante. Com o registro das solicitações de ajuda e seu atendimento por outros alunos, busca-se prover mais dados para que o professor possa avaliar a colaboração, limitação indicada pelos participantes da entrevista.

A plataforma terá um conceito de level design em cada disciplina, que será vinculado à obtenção de ambas as categorias de $X P$ : o vinculado à realização de desafios e o vinculado à colaboração. A liberação de desafios ou de recursos dentro da plataforma estará vinculada ao atingimento de um determinado nível. Um recurso poderá ser um material necessário para estudo, ou mesmo um melhoramento estético, com a personalização do avatar do usuário na plataforma.

Uma sequência típica de uso da plataforma no conceito apresentado pode ser visualizada no storyboard a seguir, que foi construído como um protótipo navegável de média fidelidade na plataforma online Figma. Um usuário, aluno do Ensino Médio, efetua seu login na plataforma e verifica a presença de desafios na disciplina de Biologia (Figura 4). Ao entrar, verifica que há um desafio do tipo captura, que envolve obter uma foto de um pássaro de determinada espécie (Figura 5).
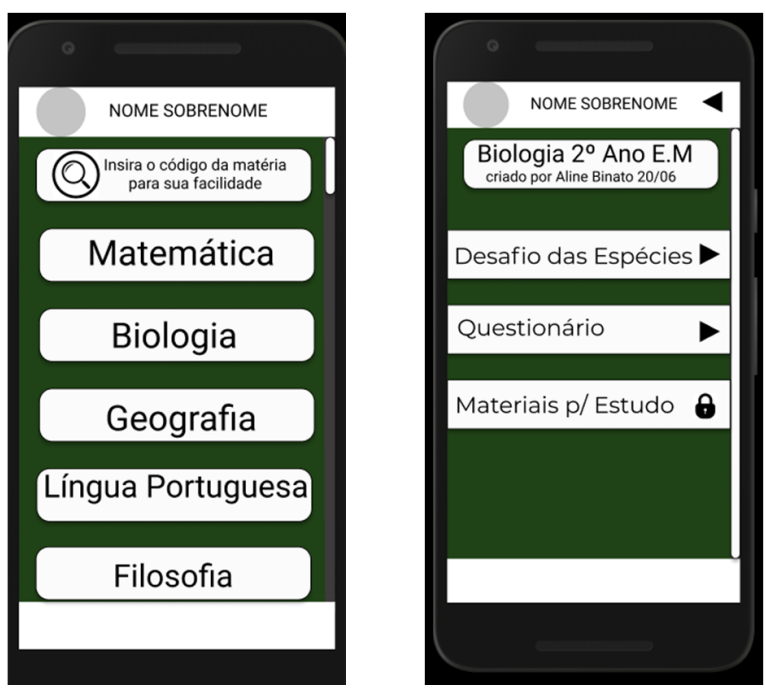

Figura 4: Visualização de desafios disponíveis
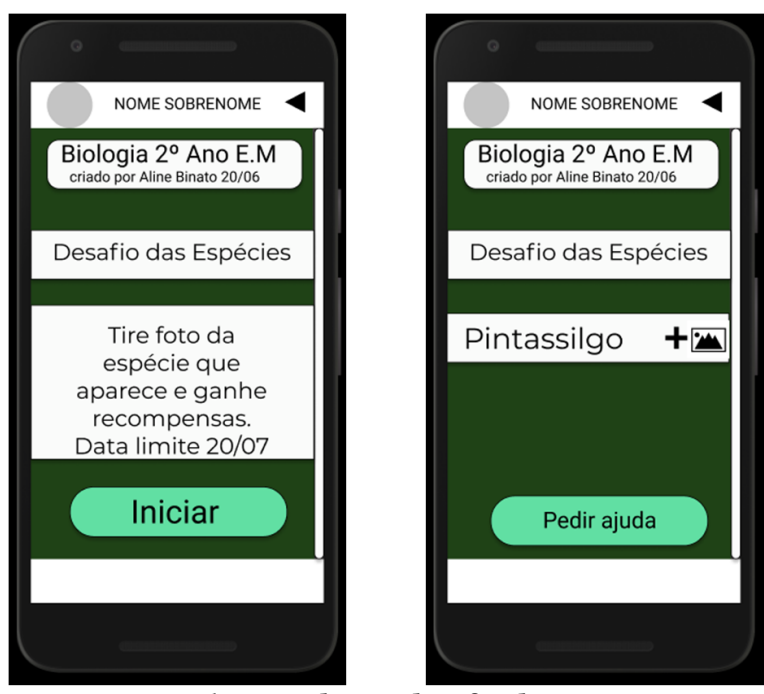

Figura 5: Visualização de um desafio do tipo Captura

Deve-se observar que, na Figura 4, um recurso específico está bloqueado ("Materiais para estudo"), exemplificando a mecânica de liberação de recursos pelo aumento do level do participante. Supondo que o participante precise de ajuda para resolver o desafio, ele irá ativar a opção "Pedir ajuda". Na Figura 6, a solicitação feita para um contato à escolha do participante é apresentada, e a resposta do mesmo por meio de mensagens para combinar o local em que a ajuda vai ser prestada.
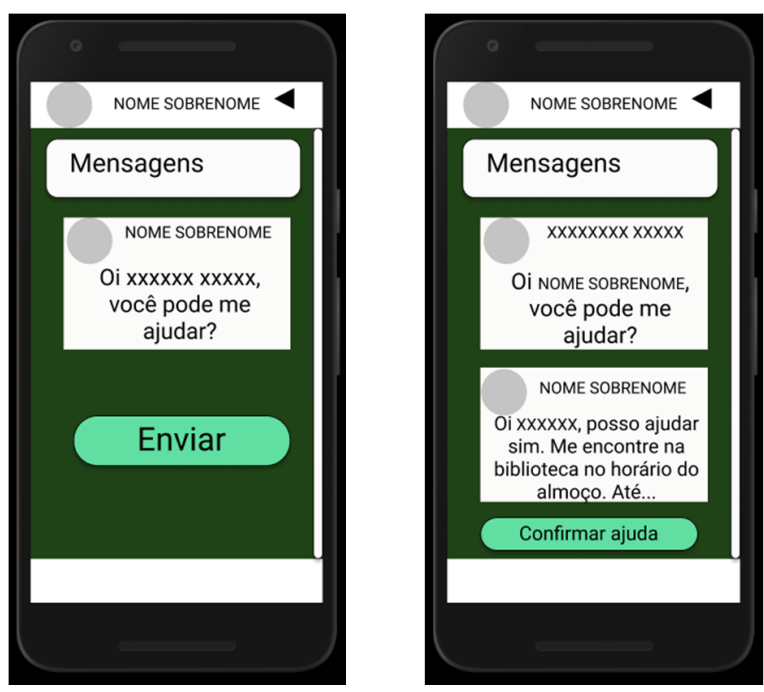

Figura 6: Solicitação e confirmação de ajuda

Uma vez que os participantes estejam próximos, evento esse que será identificado pelo sistema de geolocalização dos celulares que estarão executando a plataforma, a ajuda poderá ser confirmada pelo solicitante, evento que produzirá uma quantidade de $X P$ vinculada à colaboração para o participante que prestou a ajuda. 


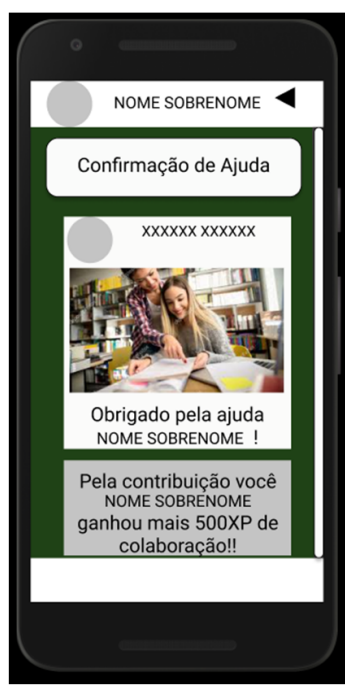

Figura 7: Confirmação da ajuda prestada e bonificação correspondente

Voltando ao cumprimento da tarefa em si, uma vez que o aluno efetue a captura solicitada (no caso, a foto de um pintassilgo), a tarefa fica registrada, pendente de validação pelo professor responsável por propor o desafio (Figura 8). Cabe ressaltar que, com a composição de tarefas de diferentes tipos, a tarefa poderia ser vinculada a um tipo check-in exigindo, por exemplo, que o participante estivesse localizado em algum dos parques situados nas proximidades da sua escola para cumprimento da tarefa.
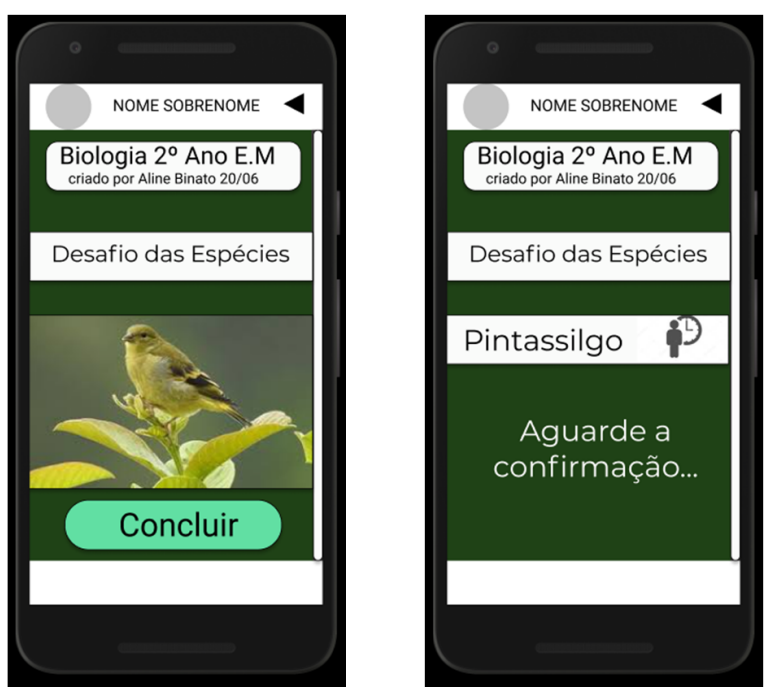

Figura 8: Execução do desafio e pendência de confirmação

Uma vez que a tarefa seja validada pelo professor, o aluno poderá, ao clicar na mesma, visualizar o status da bonificação atribuída (Figura 9).

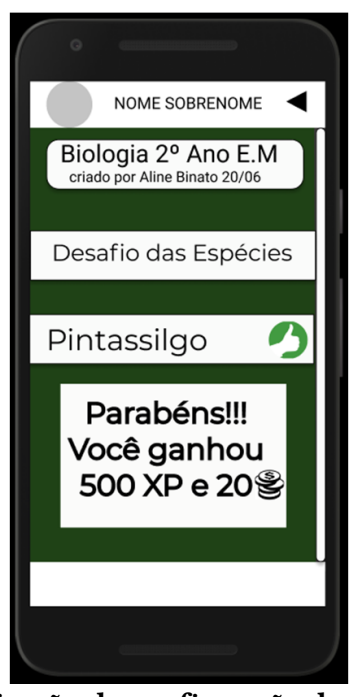

Figura 9: Visualização da confirmação do cumprimento da tarefa

A visualização do status do participante, que envolve seu level atual, requisitos para passar ao próximo level, e ações disponíveis, é apresentada na Figura 10. Deve-se destacar que o requisito para passar de um level a outro envolve necessariamente o atingimento de uma quantidade de pontos de colaboração, embora esse valor seja personalizável pelo professor. Ao acessar a opção "Progressos", o nível de XP de colaboração em cada disciplina é apresentado de forma separada.
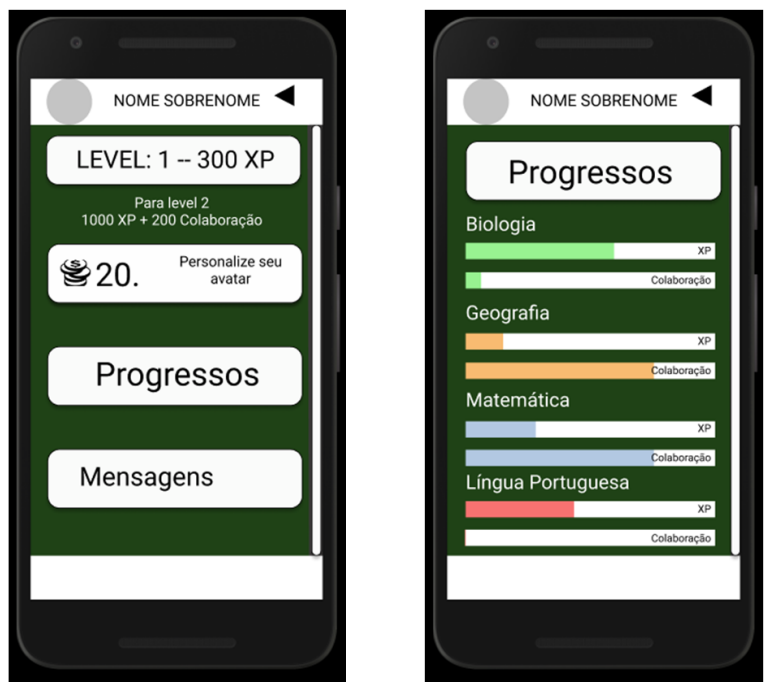

Figura 10: Visualização do level atual e nível de XP em cada disciplina

\section{Considerações finais}

Neste artigo foi apresentado o processo de design da plataforma Kaya, que visa preencher uma lacuna identificada na literatura: a ausência de sistemas baseados em dispositivos móveis para apoio ao processo de ensino-aprendizagem, com 
aspectos gamificados, e que fomentem a colaboração entre participantes.

No desenvolvimento do projeto, adotou-se um processo iterativo e incremental [19] que, até o presente momento, tem produzido bons resultados. As técnicas de levantamento empregadas, entrevistas e questionários, são de uso corrente na prática do Design de Interação, porém, ao serem projetadas levando em consideração os padrões de comportamento dos futuros jogadores [18], na perspectiva dos seus professores, permitiram incorporar com sucesso aspectos colaborativos à atividade gamificada. Como lições aprendidas, é possível acrescentar que, por um lado, o uso da análise das entrevistas com técnicas da Teoria Fundamentada em Dados, muitas vezes restrita a pesquisadores com experiência no uso das técnicas na academia, pode limitar a reprodução do método por profissionais com experiência de mercado. Por outro lado, o acesso facilitado ao campo e a pesquisadores em formação que serão potenciais jogadores, criou uma situação facilitadora para a utilização do design participativo das mecânicas de jogo.

Evidentemente, a verificação da efetividade da plataforma ainda será alvo de trabalhos futuros. Inicialmente, é planejado o refinamento do protótipo por meio de sessões preliminares de playtest antes do desenvolvimento. Do ponto de vista da Games User Research (GUR), a avaliação do comportamento e padrões de jogo dos futuros jogadores, em especial como eles adotarão as mecânicas de colaboração propostas, também será prevista em novos trabalhos.

\section{REFERÊNCIAS}

[1] Paulo E. Battistela, Christiane G. von Wangenheim, and João M. Fernandes. 2014. Como jogos educacionais são desenvolvidos? Uma revisão sistemática da literatura. In Anais do WEI 2014.

[2] Edda Bomtempo. 2017. A brincadeira de faz de conta: lugar do simbolismo, da representação, do imaginário. In fogo, brinquedo, brincadeira e a educação. Cortez, São Paulo.

[3] Liands Carvalho. 2017. O potencial exploratório da Geolocalização em games. Temática 13, 4 (2017), 242-251.

[4] Kathy Charmaz. 2009. A construção da teoria fundamentada: guia prático para análise qualitativa. Artmed, Porto Alegre.

[5] Douglas B. Clark, Emily E. Tanner-Smith, and Stephen S. Killingsworth. 2016. Digital Games, Design, and Learning: A Systematic Review and Meta-Analysis. Rev. Educ. Res. 86, 1 (2016)

$79-122$. DOI:https://doi.org/10.3102/0034654315582065

[6] Esteban Clua and João Ricardo Bittencourt. 2004. Uma nova concepção para a criação de jogos educativos. In Anais do SBIE 2004.

[7] Leandro Demenciano Costa. 2010. O que os jogos de entretenimento têm que os educativos não têm - 7 princípios para projetar jogos educativos eficientes. Editora PUC-RIO, Rio de Janeiro.

[8] Sebastian Deterding, Dan Dixon, Rilla Khaled, and Lennart Nacke. 2011. From Game Design Elements to Gamefulness: Defining "Gamification." In Proceedings of the 15th International Academic MindTrek Conference: Envisioning Future Media Environments (MindTrek '11), 9-15. DOI:https://doi.org/10.1145/2181037.2181040
[9] Wellington Ravagnani Figueiredo and Claudete Werner. 2016. A Utilização de Jogos Educativos no Âmbito Educacional. In Anais da SEINPAR.

[10] André Lemos. 2010. Jogos Móveis Locativos - Cibercultura, espaço urbano e mídia locativa. Rev. USP 86 (2010), 54-65.

[11] Ivan Moura, Carleandro Nolêto, and Igor Revoredo. 2017. ALCity: Uma Ferramenta de Autoria para o Desenvolvimento de Jogos Moveis Baseados em Localização para Apoiar o Processo de Ensino. In Anais do XXVIII Simpósio Brasileiro de Informática na Educação.

[12] Aline Nunes Ogawa, Ana Carolina Tomé Klock, and Isabela Gasparini. 2016. Avaliação da gamificação na área educacional: um mapeamento sistemático. In Anais do XXVII Simpósio Brasileiro de Informática na Educação (SBIE 2016).

[13] Ruan Pierre Oliveira, J. Antão B. Moura, Marcelo A. de Barros, Ana Carolina Policarpo Cavalcante, and Francisco Barbosa Jr. 2016. Gamificação e Crowdsourcing no Combate Sustentável ao Aedes aegypti. In Anais do XXVII Simpósio Brasileiro de Informática na Educação (SBIE 2016).

[14] Seymour Papert. 1980. Mindstorms: children, computers and powerful ideas. Basic Books, New York.

[15] Frederico Pires Pinto and Silvano Maneck Malfatti. 2016. Metodologias baseadas no uso de geolocalização e dispositivos móveis para o desenvolvimento de novas práticas educacionais. In Anais do XV Simpósio Brasileiro de Fogos e Entretenimento Digital.

[16] Marc Prensky. 2001. Digital Game-Based Learning. McGraw-Hill Pub. Co., Washington.

[17] Penelope Sweetser and Daniel Johnson. 2004. PlayerCentered Game Environments: Assessing Player Opinions, Experiences, and Issues. In Entertainment Computing ICEC 2004, 321-332.

[18] Jonathan Sykes and Melissa Federoff. 2006. Player-centred Game Design. In CHI '06 Extended Abstracts on Human Factors in Computing Systems (CHI EA '06), 1731-1734. DOI:https://doi.org/10.1145/1125451.1125774

[19] Vero Vanden Abeele, Bob De Schutter, Luc Geurts, Stef Desmet, Jeroen Wauters, Jelle Husson, Lieven Van den Audenaeren, Frederik Van Broeckhoven, Jan-Henk Annema, and David Geerts. 2012. P-III: A Player-Centered, Iterative, Interdisciplinary and Integrated Framework for Serious Game Design and Development. In Serious Games: The Challenge, 82-86.

[20] L. S. Vygotsky. 2001. A construção do pensamento e da linguagem. Editora Martins Fontes, São Paulo.

[21] Lev S. Vygotsky. 2016. Play and Its Role in the Mental Development of the Child. In International Research in Early Childhood Education. 3-25. 